\title{
First Steps of in Situ Surface-Enhanced Raman Scattering During Shipboard Experiments
}

\author{
Péron, Olivier ${ }^{1}$; Rinnert, Emmanuel ${ }^{1,{ }^{*}}$; Colas, Florent ${ }^{1}$; Lehaitre, Michel ${ }^{1}$; Compère, Chantal ${ }^{1}$ \\ ${ }^{1}$ IFREMER, Service Interfaces et Capteurs, BP 7029280 Plouzané, France \\ *: Corresponding author : E. Rinnert, tel: (+33)298224161, fax: (+33)298224535, email address : \\ Emmanuel.Rinnert@ifremer.fr
}

\begin{abstract}
:
It is shown that the surface-enhanced Raman scattering (SERS) technique can be applied to detect organic molecules during in situ experiments. To this purpose, we used trans-1,2-bis(4pyridyl)ethylene (BPE) as a target molecule. Adsorbed on the SERS chemosensor surface and excited under laser, the vibration modes of the molecules can be identified. SERS chemosensors are based on quartz substrates functionalized by silanization and partially coated with gold nanoparticles. SERS measurements during shipboard experiments were made with a home-made in situ Raman spectrometer connected to a marinized micro-fluidic system. The device was designed to host chemosensors in order to ensure measurements with a flow cell. A theoretical limit of detection was estimated in the range of picomolar $(\mathrm{pM})$ concentrations based on Freundlich isotherm calculations.
\end{abstract}

Keywords: Surface-enhanced raman scattering; sers; chemosensors; flow cells; shipboard experiments; in situ measurements; freundlich isotherm 


\section{Introduction}

Since the beginning of the $21^{\text {th }}$ century, sea water in situ methods have been developed as in the detection of the organic compounds responsible of the ocean pollution, as in the field of the discovery of new fossil energy. The in situ measurements and the common sampling techniques can be used concomitantly to improve data processing on natural samples. The latter consists in taking water samples for analysis directly aboard the ship or some time later at the laboratory. Some drawbacks arise using such technique: sample contamination, difficulties to maintain the global environment of the sample and variation in time and space of many parameters (Prien, 2007). On the contrary, in situ measurements provide instantaneous data respecting the time and space components. The interests of in situ analytical measurements are: i) a limitation of the modification of unstable species, especially for the deep sea measurements when the time between the sampling and the analysis on board or on shore may be as much as several hours ii) and a better resolution in time and space dues to high frequency measurements and direct analysis (monitoring).

In situ optical and spectroscopic techniques are well adapted to the measurements of chemical parameters in natural seawater because they provide molecular information and are easily marinized.

Vibrational spectroscopy techniques allow the identification of a wide variety of chemical compounds. Molecule vibrations give fingerprints that allow their identification. Because of huge absorption by water molecules, infrared spectroscopy is not suitable for in situ measurements. In the opposite, Raman scattering spectroscopy can provide vibrational spectra by exciting molecules in a visible spectral range that ensures in situ measurements. But the major disadvantage is that Raman scattering is very weak. Thereby, in the scope of a molecule detection at low concentration, surface-enhanced Raman scattering (SERS) effect is an alternative to the low efficiency of the Raman scattering. Indeed, SERS is a very sensitive technique with an exaltation factor up to $10^{6}$ fold the normal Raman intensity (Fleischmann et al., 1976; Jeanmaire et al., 1977 and Albrecht et al., 1977). The monochromatic light excites the modes of the surface plasmon of the nanostructured metallic film. Then, an intense local electromagnetic field is created. This field can be relaxated by energy transfer from the surface plasmons to the molecules by evanescent waves. The Raman scattering of the excited molecules can be detected and the adsorbed molecules identified. Actually, molecule detection with an environmental interest can be achieved.

Works were carried out using Raman spectroscopy i) in laboratory and ii) in situ.

i) In the investigation of chemical pollutions, such as PAHs at low (ppm) or traces concentration (ppb) in sea-water, surface-enhanced Raman scattering (SERS) effect reveals an immense potential regarding the marine environment and can be considered as an alternative to the inherent low cross-section of normal Raman scattering. In order to carry out in situ measurements, a SERS optode was developed (Murphy et al., 2000). Within the scope of screening development, a solution of five PAHs in sea-water with LODs of $37.5 \mu \mathrm{M}$ and $0.1 \mu \mathrm{M}$ for naphthalene and pyrene respectively, was analyzed in laboratory (Schmidt et al., 2004). Furthermore, experiments simulating real conditions of pressure and temperature in hydrothermal vent fluids were performed in laboratory for the measurement of sulfate, carbonate and nitrate using Raman spectroscopy (Battaglia et al., 2004).

ii) A laser Raman spectrometer was deployed on remotely operated vehicles (ROVs) with successful operation at $3600 \mathrm{~m}$ depth. Raman measurements were performed on injected liquid $\mathrm{CO}_{2}$ stocked into an inverted beaker (Brewer et al., 2002). Study was proceeded with a deep sea Raman spectrometer to characterize a $\mathrm{CO}_{2}$ sequestration method in deep ocean (White et al., 2006a). In situ Raman analyses of hydrothermal vent fluids collected into an open-bottomed sampling box were achieved (White et al., 2006b). In situ Raman measurements of synthetic gas hydrates formed in an ocean environment were injected into the cell at ocean depths of 500 to 1000 m (Hester et al., 2006). In situ Raman measurements of natural gas hydrates collected in a cell at the summit of southern Hydrate Ridge were also carried out (Hester et al., 2007). 
Other in situ spectroscopic and optical techniques were developed. Concerning infrared chemical sensor technology, Beyer et al. (2003) presented the development of a mid-infrared spectrometer based on attenuated total reflection (ATR) for detecting chlorinated hydrocarbons. In laboratory, a limit of detection (LOD) of $900 \mathrm{ppb}$ was achieved for tetrachloroethylene thanks to a silver halide fiber sensor coated with polymers. A miniaturized Fourier transform infrared (FT-IR) spectrometer for in situ underwater detection of polycyclic aromatic hydrocarbons (PAHs) and chlorinated hydrocarbons was developed by Kraft et al. (2003). Methane sensor using surface plasmon resonance (SPR) technique based on refractive index change was developed by Boulart et al. (2008).

Here, the purpose of the paper is to present the feasibility of SERS measurements during shipboard experiments with an home-made in situ Raman spectrometer connected to a marinized micro-fluidic system. Such measurements were performed with a view to apply this technique to the detection of molecules of environmental interest in sea water. On our knowledge, the present work describes for the first time in situ SERS measurements obtained during shipboard experiments. SERS spectra of trans-1,2-Bis(4-Pyridyl)Ethylene (BPE) adsorbed on the chemosensor surface were in situ recorded down to $20 \mathrm{~m}$ depth. The BPE is currently used by the SERS community as molecule probe (Billot et al., 2006; Sun and Grundmeier, 2006; Abell et al., 2009 and Sahoo et al., 2009). These spectra were analyzed using the empirical Freundlich formulation and a LOD was estimated.

\section{Material and methods}

\subsection{Instrumentation}

The marinized system (Figure 1) that allows in situ Raman measurements of dissolved matter is composed of 4 elements:

- the host structure to ensure safely launching and to implement accessories,

- the main part containing opto-electronic components (instrument body),

- the optode connected by optical fibers (optode) and

- the fluidic system composed of a flow cell and a marinized micro-fluidic system. 


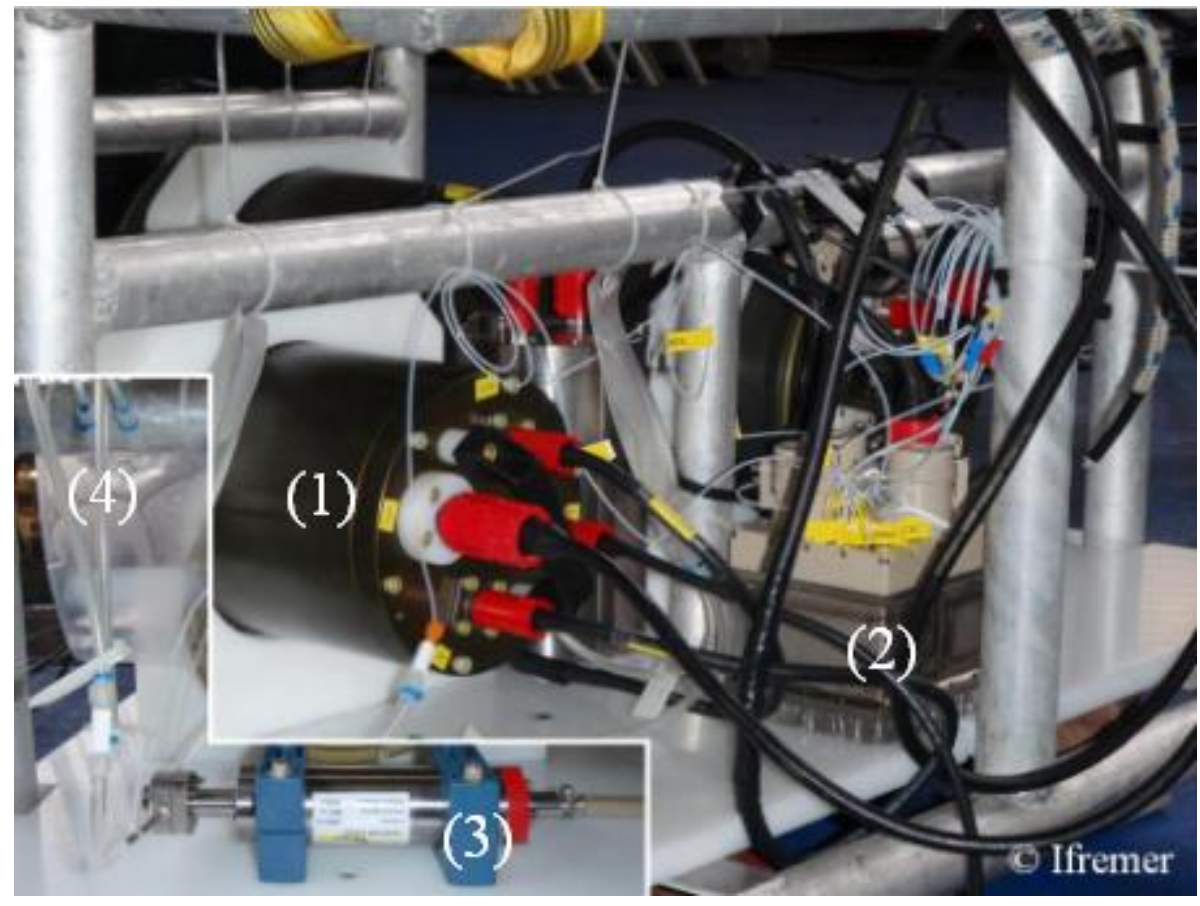

Figure 1: The host structure with (1) the instrument body, (2) the marinized microfluidic system, (3) the optode connected by optical fibers (optode) and the flow cell and (4) a plastic bag.

\subsubsection{The host structure}

The square structure is composed of welded aluminum tubes to operate the system in safety conditions (Figure 2 a). A polypropylene base plate is screwed to host equipments. Many holes are made on this plate to avoid any pounding in heavy sea conditions. The host structure is operated by an on-board winch equipped with a cable that ensures data communication by optical fibers and power supplying by electric wires (Figure 2 b).

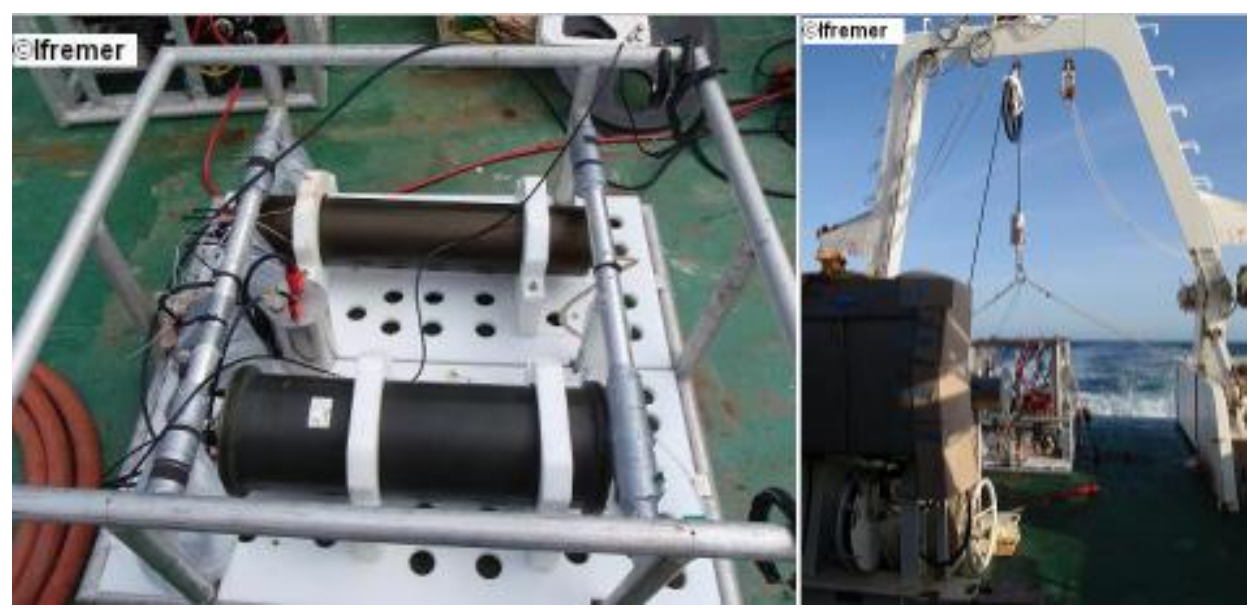

Figure 2: The operational structure used to host Raman spectrometer and accessories in sea-cruise. a) the welded aluminum tubes structure and the Raman spectrometer (on the top). b) the host structure connected to the on-board winch. 


\subsubsection{The instrument body}

The Raman spectrometer was firstly developed in collaboration with Jobin-Yvon Horiba SAS during the Sofie, Mispec and Hermes European Projects (Sofie, Mispec and Hermes). It consists in a laser diode (BRM-785, B\&WTEK) emitting at $785.4 \mathrm{~nm}$, an axial spectrograph as the system reported by Lehaitre et al. (1997) coupled to a CCD detector (DU440A-FI, Andor) driven by an embedded computer. Since these European Projects, all opto-electronic components have been housed in a single anodized aluminum cylinder $(900 \mathrm{~mm}$ long I $180 \mathrm{~mm}$ diameter). DC-DC converters are used to supply power from the surface to electric components. An embedded computer Wafer LX-800 allows system monitoring from the surface in real-time. Data are collected on an hard disk drive and also transmitted to the surface computer. The bi-directional communication is ensured through more than 300 meters of cable by Ethernet connection thanks to fiber optic multiplexers. The embedded computer allows not only Raman spectra collection but also provides intrinsic instrument parameters like CCD temperature, system temperature and relative humidity monitoring.

This part has been designed and tested to withstand pressure environment for operation down to 3000 meters.

\subsubsection{The optode}

The optode is based on a probe designed in the frame of the European Projects Sofie and Mispec by Jobin-Yvon Horiba SAS and by Technische Universität Berlin in collaboration with Ifremer teams. It contains lenses, collimator and filters to focus laser on sensing substrates and to collect back-scattered Raman light. The Raman back-scattered light is isolated by a two stage edge filters. The optode is connected to the instrument body by optical fibers composed of a single fiber for laser excitation and a bundle of 7 fibers for Raman scattered signal collection. The optode has been more detailed in Péron et al. (2009a). This part has been designed and tested to withstand pressure environment for operation down to 3000 meters.

\subsubsection{The fluidic system}

A flow cell of stainless steel AISI $316 \mathrm{~L}$ is coupled to the in situ Raman spectrometer (Figure 3). It consists in an input/output flowthrough channel, a BK7 window and a mobile part on which the SERS substrate can be mounted. The chemosensor is stuck on a piston whose position can be adjusted with a screw. The laser beam can then be focused precisely onto the substrate. O-rings around the piston and the window ensure the waterproofness of the flow cell.

The flow cell is connected to an Ifremer home-made marine micro-fluidic device (Vuillemin et al., 2009). It allows the injection of different solutions into the flow cell. It is composed of three peristaltic pumps and eight electrovalves. The formers can turn clockwise and anticlockwise and their speed can be adjusted. The latter can be set up in two positions (open or closed). The whole fluidic system is driven by a computer.

The fluidic path is shown in Figure 4. The solutions to be injected in the system are stocked in $250 \mathrm{~mL}$ plastic bags purchased from Fisher Bioblock. Two trash bags $(250 \mathrm{~mL})$ are placed in the marinized micro-fluidic system to avoid pollution: one behind a marinized peristaltic pump for rinsing the manifolds and another one at the flow cell output. Five solution bags are connected to the electrovalves. Three contain BPE solutions, one ethanol for calibrating the system and one distilled water.

This system allows analyzing directly the seawater, different solutions stocked in plastic bags or a mixture of both. 

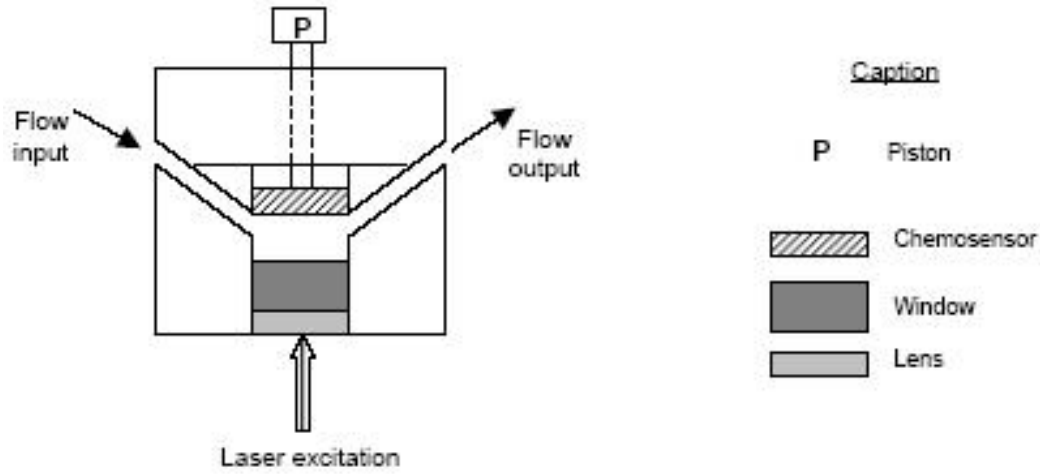

Figure 3: Scheme of the flow cell and the corresponding caption.

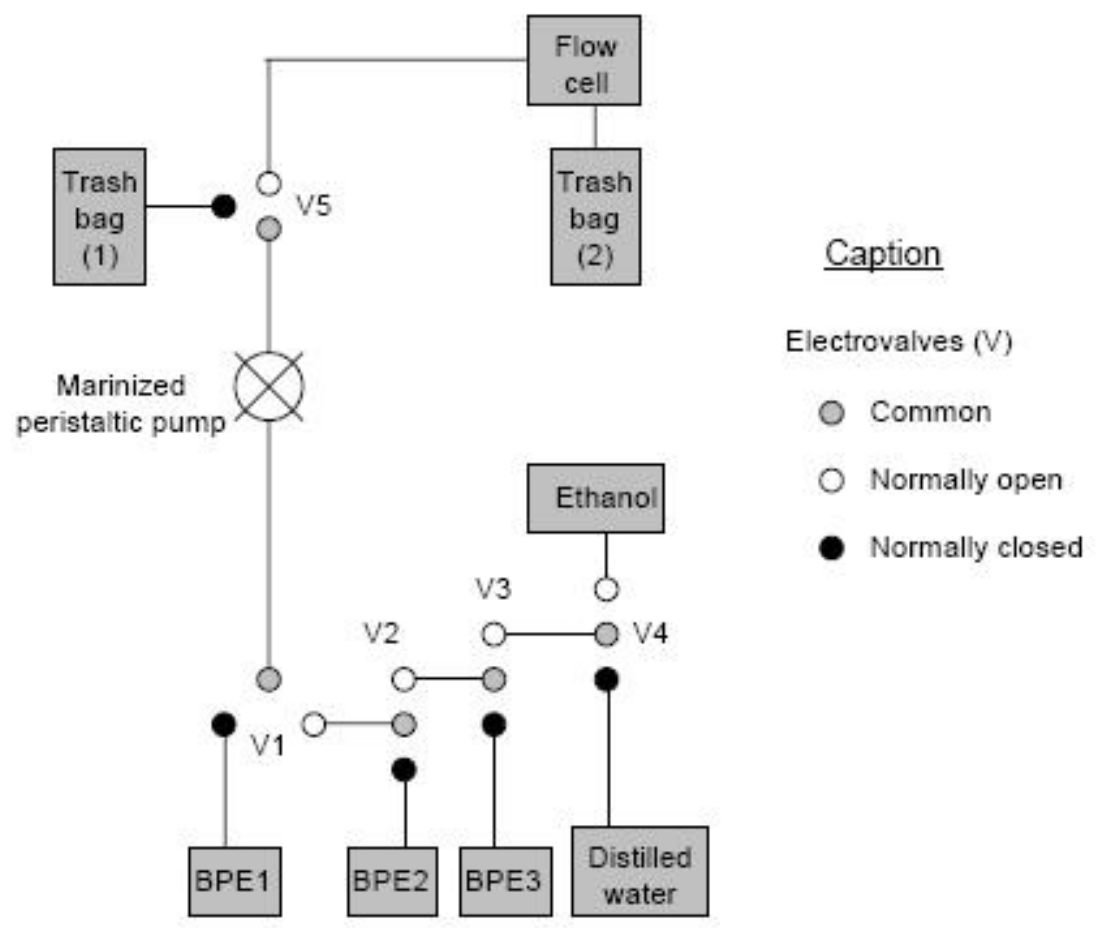

Figure 4: Scheme of the fluidic path and the corresponding caption.

\subsection{Gold nanoparticles, SERS substrates and target solutions}

Suspensions of gold nanoparticles were prepared according to the method described by Frens (1973). Such a technique was used in different studies (Lee et al., 1982; Keating et al., 1999 and Seitz et al., 2003) and consists in the reduction of $\mathrm{HAuCl}_{4}$. After the addition of a reducing agent, the gold particles start to form during a process known as nucleation and subsequently grow. The procedure is detailed elsewhere (Péron et al., 2009b).

The SERS substrates were prepared by immersion. First, clean quartz substrates of $8 \mathrm{~mm}$ diameter and $0.8 \mathrm{~mm}$ thickness from Heraeus were vertically immersed in methanol solution of 3-MercaptoPropyl triMethoxy Silane (MPMS) according to the results obtained by Seitz et al. (2003). After silanization, they were vertically dipped into the colloidal suspension of gold nanoparticles. Figure 5 presents a scheme of the SERS substrate synthesis procedure. 
The target solutions were prepared by dissolving solid trans-1,2-Bis(4-Pyridil)Ethylene (BPE) purchased from Fluka in distilled water. Three solutions of concentrations $10^{-4} \mathrm{~mol} . \mathrm{L}^{-1}$ (BPE1), $2.5 \times 10^{-4} \mathrm{~mol}^{-1} \mathrm{~L}^{-1}$ (BPE2) and $5 \times 10^{-4} \mathrm{~mol}^{-1} \mathrm{~L}^{-1}$ (BPE3) were prepared.
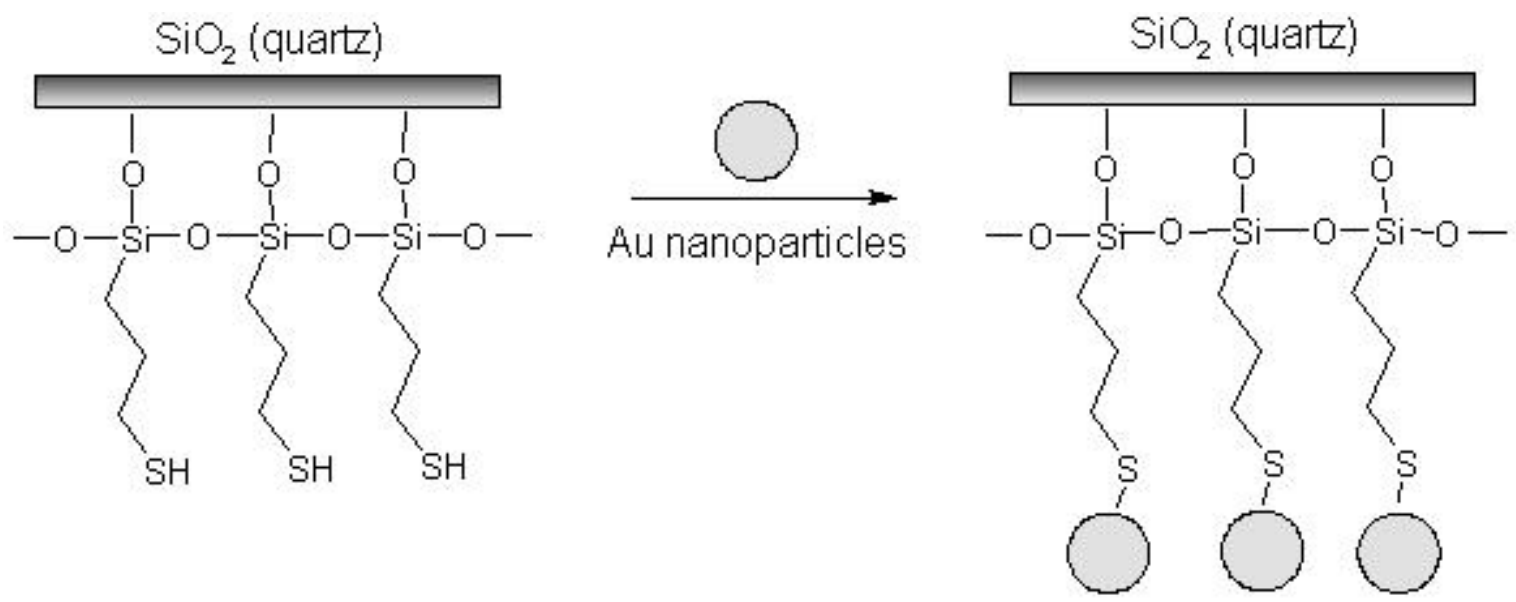

Figure 5: Schematic representation of the SERS substrate silanization procedure and immersion in gold colloidal nanoparticles.

\subsection{Experiments}

The in situ spectrometer instrument was deployed in South Brittany coastal waters at $47^{\circ} 39^{\prime} \mathrm{N}-3^{\circ} 25.7^{\prime} \mathrm{W}$ (WGS84 geodesic system) from the oceanic vessel "Thalia". The measurements were performed down to $20 \mathrm{~m}$ depth. The system was coupled to a CTD probe (Seabird, SBE 25) which measured the conductivity, temperature and depth of the seawater. At first, the kinetics of the solution injection were studied to ensure that spectroscopic measurements are obtained after the flow cell homogenization. To do so, solution of $96 \%$ ethanol was injected into the flow cell, which was then rinsed by distilled water. BPE could not be used for this experiment: its adsorption onto the chemosensor is irreversible. Ethanol was also chosen because of its large Raman scattering cross-section to ensure signal recording with a minimal SERS effect. Then, the three BPE solutions BPE1, BPE2 and BPE3 were analyzed by our system. The solutions were injected by increasing concentration.

\section{Results and discussion}

\subsection{Injection kinetics}

In order to estimate the time of the flow cell homogenization during in situ conditions, the cell was filled with ethanol. Distilled water was then injected and Raman spectra were recorded during the rinse. A kinetic study was then performed to estimate the injection time. Results are presented in Figure 6 . The distilled water was injected at time $t_{0}$ and the first recording was done after $20 \mathrm{~s}$ which corresponds to the transit time of the solution in the manifold from plastic bags to the flow cell. 


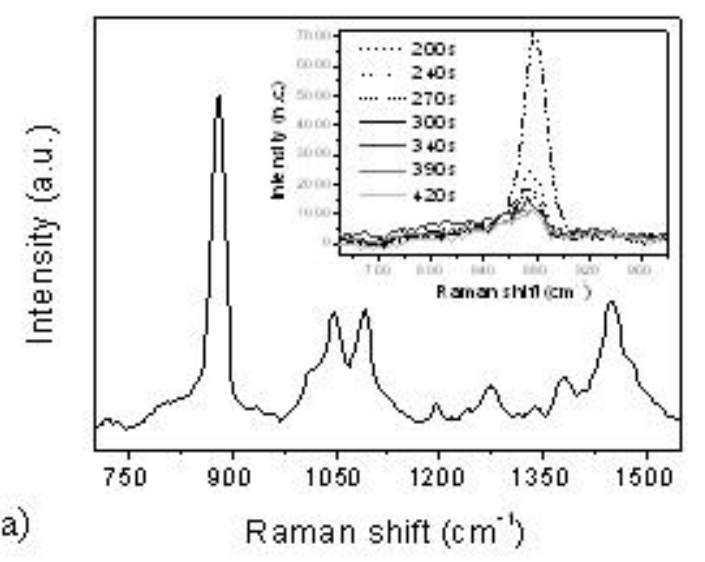

Figure 6: a) Raman spectrum of the ethanol solution and decrease of the $880 \mathrm{~cm}^{-1}$ band as a function of the rinsing time with distilled water in inset. Integration time of $20 \mathrm{~s}$. b) The decrease of the $880 \mathrm{~cm}^{-1}$ band intensity versus time and the corresponding fit from $200 \mathrm{~s}$. In inset, the evolution of the band intensity versus time. Figure 6 a) shows the Raman spectrum of the ethanol solution and the inset figure the evolution of the $880 \mathrm{~cm}^{-1}$ band intensity as distilled water is injected. The strong band located at $880 \mathrm{~cm}^{-1}$ is assigned to the $\mathrm{C}-\mathrm{C}-\mathrm{O}$ stretching band. The stretching vibrations of the alcohol C-O group are located at $1000-1200 \mathrm{~cm}^{-1}$. Hydrogen bonding leads to a slight shift of this band to shorter wavenumber: saturated primary alcohols, like ethanol, absorb strongly in the region 1000-1090 $\mathrm{cm}^{-1}$ (Socrates, 2001). The bands located at 1380 and $1450 \mathrm{~cm}^{-1}$ are assigned to the angular bending of the methylene group. This signal is probably not exalted and corresponds only to the Raman scattering of ethanol molecules in the cell. The strongest band $\left(880 \mathrm{~cm}^{-1}\right)$ was used for this study and its Raman signal intensity was normalized with the maximum signal obtained at the beginning of the experiment.

The evolution of the band intensity versus time is presented Figure 6 b (inset). A slight decline can be observed until $200 \mathrm{~s}$. Then, the signal sharply decreases until it reaches a plateau. Note that the error bar, estimated as the noise, is in the range of symbol size.

The decrease of the band intensity from $200 \mathrm{~s}$ was fitted with an exponential decay (Figure 6 b). A time constant $\tau=28 \pm 3 \mathrm{~s}$ was then calculated. The flow cell is then considered as empty of ethanol after $\mathrm{t}=200+3 \tau \sim 300 \mathrm{~s}$.

In conclusion, this study demonstrated the ability of our system to inject solutions in the flow cell and to proceed to its analysis within few minutes, all action operated from the surface computer.

\subsection{Detection of BPE by SERS measurements}

The three solutions BPE1, BPE2 and BPE3 were analyzed by our system. The solutions were injected by increasing concentration. The spectra are shown in Figure 7. A blank spectrum measured with distilled water in the flow cell is also presented. It corresponds to the spectrum of the organic part (MPMS) of the SERS substrate. 


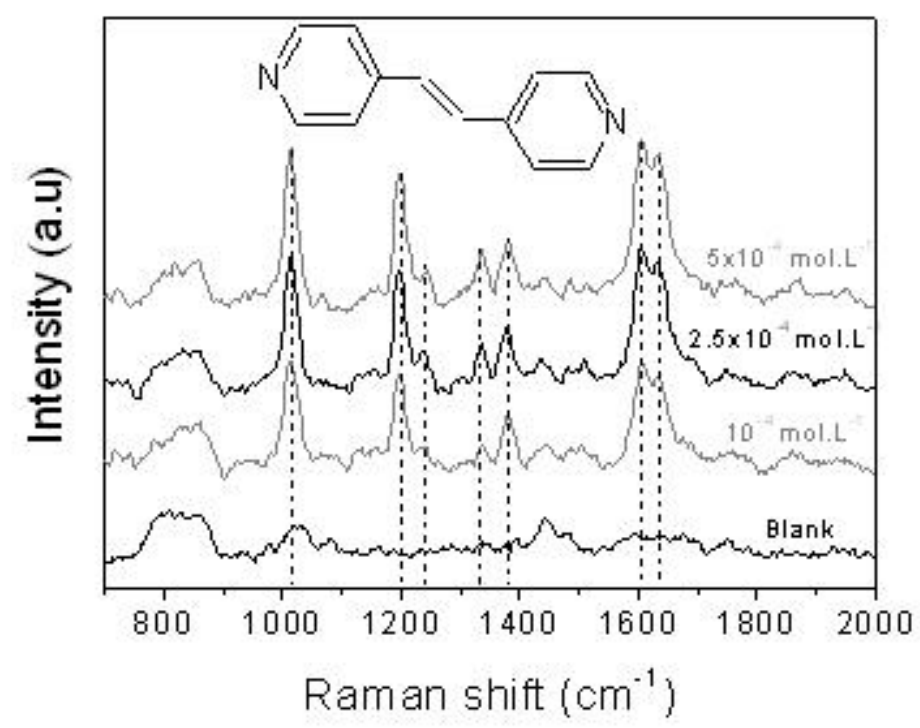

Figure 7: SERS spectra of trans-1,2-Bis(4-Pyridil)Ethylene (BPE) solutions adsorbed on chemosensor surface from 1 to $5 \times 10^{-4} \mathrm{~mol}^{-1}$ and the blank. Integration time of 20 s.

Five single bands and one doublet are assigned to the BPE molecule. The observed Raman spectra of the adsorbed BPE are in agreement with the assignment reported in the literature (Sun and Grundmeier, 2006; Zhuang et al, 2007). The band due to the aromatic ring breathing is located at $1015 \mathrm{~cm}^{-1}$. The ring breathing corresponds to the stretching and contracting of the carbon-carbon bonds. The bands at $1195-1240 \mathrm{~cm}^{-1}$ are respectively assigned to the ring vibration and the bending mode of $\mathrm{C}-\mathrm{H}$. The bands at $1335-1380 \mathrm{~cm}^{-1}$ are respectively attributed to the bending mode of $\mathrm{C}=\mathrm{C}$ and $\mathrm{C}-\mathrm{H}$. The bands of the doublet located at $1606-1636 \mathrm{~cm}^{-1}$ are respectively assigned to $\mathrm{C}-\mathrm{N}$ bending and $\mathrm{C}=\mathrm{C}$ stretching vibrations. The other minor bands are assigned to the organic matter from MPMS silanization.

The previous kinetic study showed that the time to ensure a complete exchange of the solution was about $300 \mathrm{~s}$. The increase of the $1195 \mathrm{~cm}^{-1}$ band intensity with regard to time is presented Figure 8. The study was performed on the aromatic ring vibration which presents a well spectral resolution and a high intensity. Moreover, the blank does not reveal any signal at $1195 \mathrm{~cm}^{-1}$. Note that the error bar is estimated as the noise. For each BPE concentration, the band intensity increases with time. As expected after about $300 \mathrm{~s}$ the signals do not significantly increase. 


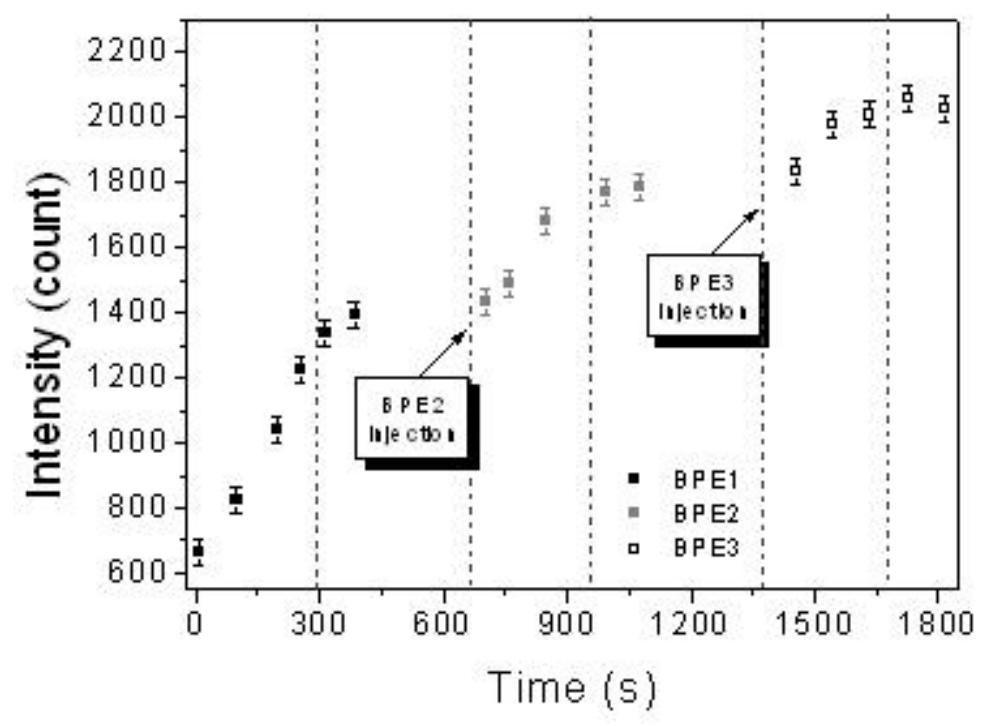

Figure 8: Intensity of the SERS band $\left(1195 \mathrm{~cm}^{-1}\right)$ versus time for BPE1, BPE2 and BPE3. The BPE injections are indicated with arrows.

The classical models that can be used to describe adsorption between the solid phase and aqueous phase at equilibrium are Langmuir (Langmuir, 1918) or Freundlich (Freundlich, 1907a) equations. The Langmuir model is used in the case of homogeneous monolayer adsorption while the empirical Freundlich model is applied for heterogeneous surfaces (Freundlich, 1928b and Meghea et al., 1998). The SEM images of the chemosensors (Péron et al., 2009b) highlight the inhomogeneous spatial distribution of the gold nanoparticles. Furthermore, the nanoparticle size is in the range 40-100 nm including hot spots. Thereby, the empirical model is applied here to describe the adsorption of the BPE molecules onto the chemosensor surface. Figure 9 presents the $1195 \mathrm{~cm}^{-1}$ band intensity with regard to the concentration. Assuming that the band intensity was proportional to the amount of molecules onto the surface, the data were fitted with the Freundlich law. It is given by the Eq. 1:

$$
\mathrm{I} \propto \eta=\mathrm{K}_{\mathrm{F}} \times[\mathrm{BPE}]^{\mathrm{n}} \quad \text { Equation } 1
$$

where $\eta$ is the adsorbed quantity $\left(\mathrm{mol} . \mathrm{kg}^{-1}\right)$, [BPE] the concentration of adsorbate in the solution ( $\left.\mathrm{mol}^{\mathrm{L}} \mathrm{L}^{-1}\right), \mathrm{n}$ and $\mathrm{K}_{\mathrm{F}}$ two constants depending on the temperature, the type adsorbing and the adsorbed molecules. The Freundlich exponent, $\mathrm{n}$ (dimensionless), is indicative of the adsorption intensity; i.e. the distribution and the size of the sites. The Freundlich coefficient, $\mathrm{K}_{\mathrm{F}}\left(\mathrm{L}^{\mathrm{n}} \cdot \mathrm{mol}^{(1-n)} \cdot \mathrm{kg}^{-1}\right)$, is function of the number of sites and the ionic composition of the liquid phase (Sposito, 1980).

The results of the fit of intensity versus BPE concentration are shown in Figure 9 a). The data are in good agreement with the empirical model according to the $\mathrm{R}^{2}$ coefficient. The $\mathrm{K}$ coefficient presented is proportional to the $\mathrm{K}_{\mathrm{F}}$ Freundlich coefficient and is homogeneous to count. $L^{n} \cdot m^{-n}$. Similar experiments were carried out in laboratory to supply more experimental data. The results are shown in Figure $9 \mathrm{~b}$ ). For shipboard experiments, $\mathrm{n}$ is about 0.2 and $\mathrm{K}$ about 1300 count. $^{\mathrm{n}}$. mol ${ }^{-\mathrm{n}}$ whereas in the laboratory, $\mathrm{n}$ is about 0.1 and $\mathrm{K}$ about 700 count. $L^{n} \cdot m o l^{-n}$. 

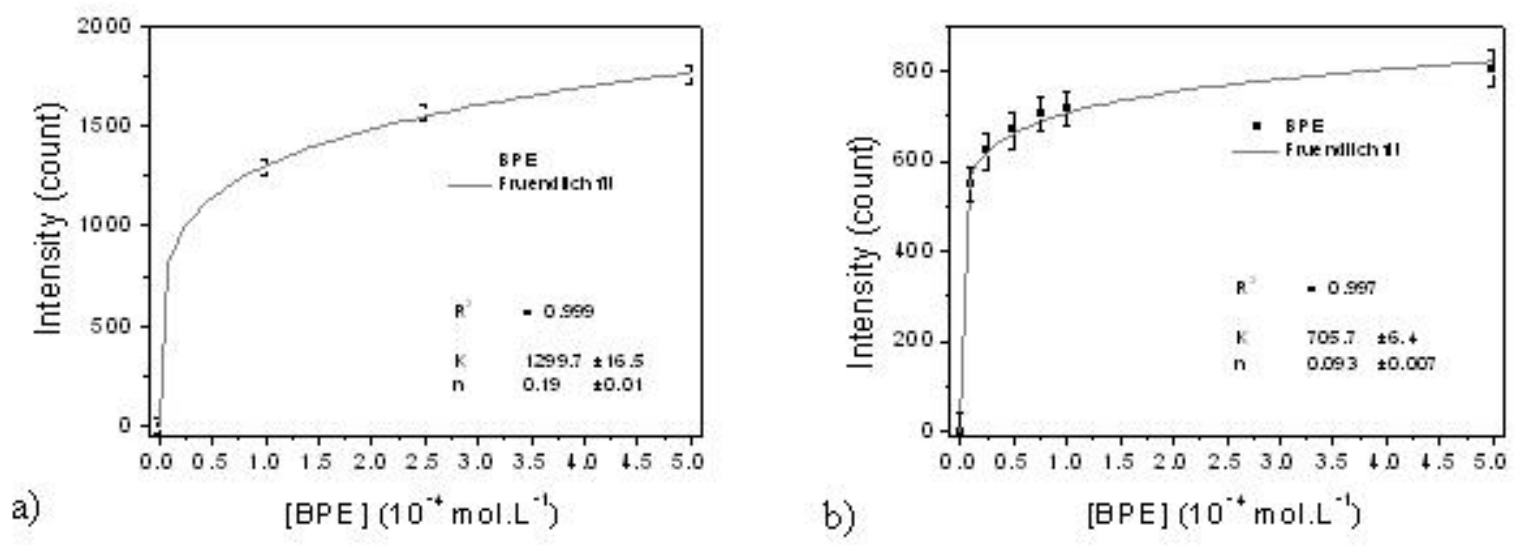

Figure 9: a) Signal intensity versus [BPE] for shipboard. b) and laboratory experiments. The error bar is estimated as the spectral noise.

The adsorption liquid-solid is referenced in the classification of Giles et al. (1960) and the obtained fits correspond to the $\mathrm{H}$ type. $\mathrm{H}$ type is considered as a typical shape for chemisorption: a strong interaction occurs between BPE molecules and the chemosensor surface. Moreover, a value of the Freundlich exponent, with $0<n<1$, is a guideline of the favorable adsorption and the surface heterogeneity (Tsai et al., 2003). BPE molecules, probably covalently grafted to the gold nanoparticles by the free nitrogen doublet, can not be desorbed from the chemosensor surface. Thereby, a same chemosensor can not be used both, to make shipboard and laboratory experiments.

For this model of curve, the slope at the origin tends towards the infinity. Indeed, assuming that the smallest detectable peak is three times the noise amplitude, a LOD of $360 \mathrm{pM}$ was estimated during shipboard experiments and a LOD of $0.5 \mathrm{pM}$ was estimated during laboratory experiments.

The surface heterogeneity in terms of adsorption sites leads to a variability of the Freundlich exponent $\mathrm{n}$. The value of the Freundlich coefficient $\mathrm{K}_{\mathrm{F}}$ depends on the Freundlich exponent $\mathrm{n}$.

In the literature, $\mathrm{K}_{\mathrm{F}}$ and $\mathrm{n}$ values of Freundlich equation depends also on temperature and increases positively with temperature (Jain, 2001; Karthikeyan et al., 2005) or decreases with increasing temperature (Gereli et al., 2006 and Qaiser et al., 2009). In our case during shipboard experiments, the CTD probe measured a sea water temperature of $12{ }^{\circ} \mathrm{C}$ and the laboratory experiments were performed at room temperature. This variation can be considered as marginal. In our opinion, the major difference obtained between $\mathrm{n}$ and $\mathrm{K}$, could be explained owing to the non reproducibility of the chemosensors in nanoparticle size and distribution: the nanoparticle size being in the range of $40-100 \mathrm{~nm}$ and randomly distributed (Péron et al., 2009b). Two hypotheses can be suggested to explain the increase of $\mathrm{K}$ and $\mathrm{n}$ in the case of the shipboard experiments:

i) hot spots give rise to intense local surface plasmon and the Raman signal of the excited molecule is more exalted.

ii) BPE adsorbed amount depends on specific surface area of Au nanoparticles. According to the heterogeneity of the nanoparticle size distribution on the chemosensors, the measured intensity is also variable. The same phenomenon has been observed elsewhere concerning adsorption on silica and activated-carbon (McKay et al., 1980; Santhi and Manonmani, 2009).

In order to obviate this non reproducibility of the gold nanoparticles, works are in progress on the SERS sensor fabrication by electron beam lithography using lift-off technique (Grand et al., 2003, 2005). This advanced lithography technique leads to nanostructures of desired size, shape and arrangement with reproducibility. 


\section{Conclusion}

Shipboard experiments were performed using surface-enhanced Raman scattering (SERS) method. The spectral fingerprint of trans-1,2-Bis(4-Pyridyl)Ethylene (BPE), as target molecule, adsorbed on chemosensor surface was obtained thanks to an home-made in situ Raman spectrometer. The latter was connected to a marinized micro-fluidic system. The chemosensor response can be fitted with the empirical Freundlich equation. The obtained fit corresponds to a model of curve which slope at the origin tends towards the infinity and a limit of detection was notified in the range of the pM concentrations. The underwater/deck communication was confirmed without lost of any data and the marinized micro-fluidic device allowed the injection of the selected solutions into the flow cell. In the immediate future, some SERS experiments are set up on molecules of environmental interest like highly toxic polycyclic aromatic hydrocarbons (PAHs).

\section{Acknowledgements}

This project was supported by ANR financing (P2IC: Discomar) and carried out in conjunction with the Laboratoire de Nanotechnologie et d'Instrumentation Optique (LNIO) Université de Technologie de Troyes (UTT). Many thanks to the captain and crew of the oceanic vessel "Thalia". We are grateful to M.-M. Danielou; E. Le Gall and M. Lunven IFREMER - DYNECO/PELAGOS (Plouzané France) for helping us for the sensor deployment. The authors acknowledge for technical assistance and Chemini development $A$. Kerboul - IFREMER - RDT/MS and the team - IFREMER - RDT/EIM (Plouzané France).

\section{References}

J.L. Abell, J.D. Driskell, R.A. Dluhyc, R.A. Trippb, and Y.-P. Zhaod. Fabrication and characterization of a multiwell array SERS chip with biological applications. Biosens. Bioelectron. 24, 3663 (2009).

M.G. Albrecht and J.A. Creighton. Anomalously intense Raman spectra of pyridine at a silver electrode. J. Am. Chem. Soc. 99, 5215 (1977).

T.M. Battaglia, E.E. Dunn, M.D. Lilley, J. Holloway, B.K. Dable, J. Marquardt, and K.S. Booksh. Development of an in situ fiber optic Raman system to monitor hydrothermal vents. Analyst 129, 602 (2004).

T. Beyer, P. Hahn, S. Hartwig, W. Konz, S. Scharring, A. Katzir, H. Steiner, M. Jakusch, M. Kraft, and B. Mizaikoff. Mini spectrometer with silver halide sensor fiber for in situ detection of chlorinated hydrocarbons. Sens. Actuators B 90, 319 (2003).

L. Billot, M. Lamy de la Chapelle, A.-S. Grimault, A. Vial, D. Barchiesi, J.-L. Bijeon, P.-M. Adam, and $P$. Royer. Surface enhanced Raman scattering on gold nanowire arrays: Evidence of strong multipolar surface plasmon resonance enhancement. Chem. Phys. Lett. 422, 303 (2006).

C. Boulart, M.C. Mowlem, D.P. Connelly, J.-P. Dutasta, and C.R. German. A novel, low-cost, high performance dissolved methane sensor for aqueous environments. Opt. Express 16, 12607 (2008).

B.T. Bowman. Conversion of Freundlich adsorption $\mathrm{K}$ Values to the mole fraction format and the use of $S_{Y}$ values to express relative adsorption of pesticides. Soil Sci. Soc. Am. J. 46, 740 (1982).

P.G. Brewer, J.D. Pasteris, G. Malby, E.T. Peltzer, S.N. White, B. Wopenka, M.O. Brown, and D. Cline. Laser Raman spectroscopy used to study the ocean at $3600 \mathrm{~m}$ depth. Eos Trans. Am. Geophys. Union 83, 469 (2002).

M. Fleischmann, P.J. Hendra, A.J. McQuillan, R.L. Paul, and E.S. Reide. Raman spectroscopy at electrode-electrolyte interfaces. J. Raman Spectrosc. 4, 269-274 (1976). 
G. Frens. Preparation of gold dispersions of varying particle size: controlled nucleation for the regulation of the particle size in monodisperse gold suspensions. Nature, Phys. Sci. 241, 20 (1973).

H. Freundlich. Ueber die Adsorption in Loesungen. Z. Phys. Chem. 57 A, 385 (1907a).

H. Freundlich. Colloid and Capillary Chemistry. E.P. Dutton and Co., New York (1928b).

G. Gereli, Y. Seki, I.M. Kusoglu, and K. Yurdakoç. Equilibrium and kinetics for the sorption of promethazine hydrochloride onto K10 montmorillonite, J. Colloid Interface Sci. 299, 155 (2003).

C.H. Giles, T.H. MacEwan, S.N. Nakhwa, and D. Smith. Studies in adsorption: Part XI. A system of classification of solution adsorption isotherms, and its use in diagnosis of adsorption mechanisms and in measurement of specific surface areas of solids, J. Chem. Soc. 111, 3973 (1960).

J. Grand, S. Kostcheev, J.-L. Bijeon, M. Lamy de la Chapelle, P.-M. Adam, A. Rumyantseva, G. Lérondel, and P. Royer. Optimization of SERS-active substrates for near-field Raman spectroscopy, Synth. Met. 139, 621-624 (2003).

J. Grand, M. Lamy de la Chapelle, J.-L. Bijeon, P.-M. Adam, A. Vial, and P. Royer. Role of localized surface plasmons in surface-enhanced Raman scattering of shape-controlled metallic particles in regular arrays, Phys. Rev. B 72, 033407 (2005).

HERMES: Hotspot Ecosystem Research on the Margins of European Seas. This project was funded by the European Commission's Framework Sixth Programme, under the priority Sustainable Development, Global Change and Ecosystems. Contract No. GOCE-CT-2005511234-1. Start: 4/1/2005. End: 3/31/2009.

K.C. Hester, S.N. White, E.T. Peltzer, P.G. Brewer, and E.D. Sloan. Raman spectroscopic measurements of synthetic gas hydrates in the ocean. Mar. Chem. 98, 304 (2006).

K.C. Hester, R.M. Dunk, S.N. White, P.G. Brewer, E.T. Peltzer, and E.D. Sloan. Gas hydrate measurements at Hydrate Ridge using Raman spectroscopy, Geochim. Cosmochim. Acta 71, 2947 (2007).

C.K. Jain. Adsorption of zinc onto bed sediments of the River Ganga: adsorption models and kinetics, Hydr. Sci. J. 46, 419 (2001).

D.J. Jeanmaire and R.P. Van Duyne. Surface Raman spectroelectrochemistry Part I. Heterocyclic, aromatic, and aliphatic amines adsorbed on the anodized silver electrode. J. Electronanal. Chem. 84, 1 (1977).

T. Karthikeyan, S. Rajgopal, and L.M. Miranda. Chromium(VI) adsorption from aqueous solution by Hevea Brasilinesis sawdust activated carbon. J. Hazard. Mater. B124, 192 (2005).

C.D. Keating, M.D. Musick, M.H. Keefe, and M.J. Natan. Kinetics and thermodynamics of Au colloid monolayer self-assembly. J. Chem. Educ. 76, 949 (1999).

M. Kraft, M. Jakusch, M. Karlowatz, A. Katzir, and B. Mizaikoff. New frontiers for mid-infrared sensors: Towards deep sea monitoring with a submarine FT-IR sensor system. Appl. Spectrosc. 57, 591 (2003).

I. Langmuir. The adsorption of gases on plane surfaces of glass, mica and platinum. J. Am. Chem. Soc. 40, 1361 (1918).

P.C. Lee and D. Meisel. Adsorption and surface-enhanced Raman of dyes on silver and gold sols. J. Phys. Chem. 86, 3391 (1982).

M. Lehaitre, N. Le Bris, A. Ouisse, and A. Belinger. Optical Fibre Spectrophotometry for in Situ Seawater Biological and Chemical Analysis. J. Mar. Environ. Eng. 4, 85-95 (1997).

G. McKay, M.S. Otterburn, and A.G. Sweeney. The removal of colour from effluent using various adsorbents- IV. Silica: equilibria and columns studies. Water Research 14, 21 (1980). A. Meghea, H.H. Rehner, I. Peleanu, and R. Mihalache. Test-fitting on adsorption isotherms of organic pollutants from waste waters on activated carbon. J. Radioanal. Nucl. Chem. 229, 105 (1998).

MISPEC: Multiparametric in situ spectroscopic measuring platform for coastal monitoring. This project was funded by the European Commission's Framework Fifth Programme, under the priority Energy, Environment and Sustainable Development. Contract No. EVK3-CT2000-00045. Start: 3/1/2001. End: 2/29/2004. 
T. Murphy, S. Lucht, H. Schmidt, and H.-D. Kronfeld. Surface-enhanced Raman scattering (SERS) system for continuous measurements of chemicals in sea-water. J. Raman Spectrosc. 31, 943 (2000).

$\mathrm{O}$. Péron, E. Rinnert, M. Lehaitre, and C. Compère. Towards in situ detection of PAH trace in sea-water using SERS-active sensors. Proc. SPIE Defense, Security \& Sensing 7312, 73120D1 (2009A).

O. Péron, E. Rinnert, M. Lehaitre, P. Crassous, and C. Compère. Detection of polycyclic aromatic hydrocarbon (PAH) compounds in artificial sea-water using surface-enhanced Raman scattering (SERS). Talanta 79, 199 (2009b).

R.D. Prien. The future of chemical in situ sensors. Mar. Chem. 107, 422 (2007).

S. Qaiser, A.R. Saleemi, and M. Umar. Biosorption of lead(II) and chromium(VI) on groundnut hull: Equilibrium, kinetics and thermodynamics study. Electron. J. Biotech. 12, 1 (2009).

P.K. Sahoo, K. Vogelsang, H. Schift, and H.H. Solak. Surface plasmon resonance in nearfield coupled gold cylinder arrays fabricated by EUV-interference lithography and hot embossing. App. Surf. Sci. 256, 431 (2009).

$\mathrm{T}$. Santhi and S. Manonmani. Removal of methylene blue from aqueous solution by bioadsorption onto Ricinus communis epicarp activated carbon. Chem. Eng. Res. Bull. 13, 1 (2009).

H. Schmidt, N. Bich Ha, J. Pfannkuche, H. Amann, H.-D. Kronfeldt, and G. Kowalewska. Detection of PAHs in seawater using surface-enhanced Raman scattering (SERS). Mar. Poll. Bull. 49, 229 (2004).

O. Seitz, M.M. Chehimi, E. Cabet-Deliry, S. Truong, N. Felidj, C. Perruchot, S.J. Greaves, and J.F. Watts. Preparation and characterization of gold nanoparticles assemblies on silanised glass plate. Colloids Surf. A: Physicochem. and Eng. Aspects 218, 225 (2003).

G. Socrates. Infrared and Raman characteristic group frequencies. John Wiley \& Sons Ltd, 94-95pp (2001).

SOFIE: Spectroscopy using Optical Flbers in the marine Environment. This project was funded by the European Commission's Framework Fourth Program, under the priority Oceanographic measurement and sampling equipment. Contract No. MAS3-97-0157. Start: 3/1/1998. End: $12 / 31 / 2000$.

G. Sposito. Derivation of the Freundlich equation for ion exchange reactions in soils. Soil Sci. Soc. Am. J. 44, 652 (1980).

G. Sun and G. Grundmeier. Surface-enhanced Raman spectroscopy of the growth of ultrathin organosilicon plasma polymers on nanoporous $\mathrm{Ag} / \mathrm{SiO}_{2}$-bilayer films. Thin Solid Films 515, 1266 (2006).

W.T. Tsai, C.W. Lai, and K.J. Hsien. Effect of particle size of activated clay on the adsorption of paraquat from aqueous solution. J. Colloid Interface Sci. 263, 29 (2003).

R. Vuillemin, D. Le Roux, J.-P. Dorval, K. Bucas,.J.-P. Sudreau, M. Hamon, C. Le Gall, and P.-M. Sarradin. CHEMINI: A new in situ CHEmical MINlaturized analyzer. Deep-Sea Research I 56, 1391 (2009).

S.N. White, P.G. Brewer, and E.T. Peltzer. Determination of gas bubble fractionation rates in the deep ocean by laser Raman spectroscopy. Mar. Chem. 99, 12 (2006a).

S.N. White, R.M. Dunk, E.T. Peltzer, J.J. Freeman, and P.G. Brewer. In situ Raman analyses of deep-sea hydrothermal and cold seep systems (Gorda Ridge and Hydrate Ridge), Geochem. Geophys. Geosyst., 7, 1 (2006b).

Z. Zhuang, J. Cheng, H. Jia, J. Zeng, X. Han, B. Zhao, H. Zhang, G. Zhang, and W. Zhao. Density functional theory calculation of vibrational spectroscopy of trans-1,2-bis(4-pyridyl)ethylene. Vib. Spectrosc. 43, 306 (2007). 